\title{
Tratabilidade do lodo biológico têxtil e produção de biogás em reator UASB em diferentes temperaturas
}

\author{
Textile biological sludge treatability and biogas \\ production in UASB reactor under different temperatures
}

Júnia Schultz', Adilson Pinheiro², Joel Dias da Silva ${ }^{3}$

\begin{abstract}
RESUMO
Neste trabalho avaliou-se o comportamento de um reator UASB em escala laboratorial (16 L) no tratamento de lodo biológico têxtil com produção de biogás, operando em diferentes temperaturas, 35 (mesofilica), 45 e 550 C (termofilica), com tempo de detenção hidráulica (TDH) constante de 24 h. O reator UASB apresentou-se apto a tratar o lodo têxtil, sendo influenciado positivamente pelo incremento da temperatura, mostrando maiores remoções nas temperaturas termofilicas e com altas taxas de remoção de todos os parâmetros físico-químicos monitorados: demanda química de oxigênio (DQO) (97\% em 45 e 55ㄷ), demanda bioquímica de oxigênio (DBO) ( $95 \%$ em $45^{\circ} \mathrm{C}$ e $94 \%$ em $55^{\circ} \mathrm{C}$ ), fósforo total (P-total) (95\% a 45 e $55^{\circ} \mathrm{C}$ ) e nitrogênio total (N-total) $(94 \%$ a 45 e 55ㅇ). Quanto à produção de biogás e à concentração de metano, os maiores valores foram observados a $45^{\circ} \mathrm{C}$. Com base nos resultados alcançados, confirmam-se a tratabilidade do lodo têxtil e a produção de biogás em UASB, com melhor performance a $45^{\circ} \mathrm{C}$.

Palavras-chave: lodo têxtil; digestão anaeróbia; reator UASB; biogás.
\end{abstract}

\begin{abstract}
The aim of this work was to evaluate the behavior of a laboratory-scale UASB reactor $(16 \mathrm{~L})$ in the treatment of textile biological sludge with biogas production, operating at different temperatures - 35 (mesophilic), 45 and $55^{\circ} \mathrm{C}$ (thermophilic) -, with constant hydraulic retention time of $24 \mathrm{~h}$. The UASB reactor was able to treat the textile sludge, being positively influenced by increasing temperature, with greater removals in thermophilic temperatures and high removal rates of all monitored physical and chemical parameters: chemical oxygen demand (COD) (97\% at 45 and $55^{\circ} \mathrm{C}$ ), biochemical oxygen demand (BOD) (95\% at $45^{\circ} \mathrm{C}$ and $94 \%$ at $55^{\circ} \mathrm{C}$ ), total phosphorus (P-total) (95\% at 45 and $55^{\circ} \mathrm{C}$ ) and total nitrogen ( $\mathrm{N}$-total) $\left(94 \%\right.$ at 45 and $55^{\circ} \mathrm{C}$ ). As for biogas production and methane concentration, the highest values were observed at $45^{\circ} \mathrm{C}$. Based on the results, textile sludge treatability and biogas production in UASB are confirmed, with best performance at $45^{\circ} \mathrm{C}$.
\end{abstract}

Keywords: textile sludge; anaerobic digestion; UASB reactor; biogas.

\section{INTRODUÇÃO}

O processo natural de decomposição da matéria orgânica na ausência de oxigênio, também conhecido como digestão anaeróbia, ocorre em vários estágios bioquímicos consecutivos, dos quais participam diferentes micro-organismos (GARCIA, 2011). Produtos intermediários como ácidos graxos, acetatos, gases, entre outros, são continuamente gerados e processados ao longo da decomposição (PEREIRA; CAMPOS; MOTERANI, 2009).

Em sistemas fechados e controlados, como biodigestores (FERNANDES et al., 2014), reatores de leito fluidizado (MOTTERAN et al., 2014), reatores operando em batelada (PINTO et al., 2014), reatores anaeróbios de fluxo ascendente e manta de lodo (Upflow Anaerobic Sludge Blanket - UASB) (SCHNEIDERS et al., 2013), o processo sofre a influência de fatores como potencial hidrogeniônico $(\mathrm{pH})$, cargas tóxicas e nutrientes (ASSUNÇÃO; VON SPERLING, 2012; PEREIRA; CAMPOS; MOTTERAN, 2013). Diferentes temperaturas também podem afetar o processo, positiva ou negativamente (KIM et al., 2012; RAMAKRISHNAN; SURAMPALLI, 2012).

Dos fatores citados, a temperatura destaca-se por estar diretamente relacionada com o processo de sobrevivência, crescimento e 口-

'Doutoranda no Programa de Pós-graduação em Biotecnologia Vegetal e Bioprocessos da Universidade Federal do Rio de Janeiro (UFRJ) - Rio de Janeiro (RJ), Brasil. 2Doutor em Física e Química Ambiental. Professor do Programa de Pós-graduação em Engenharia Ambiental no Centro de Ciências Tecnológicas da Fundaçăo Universidade Regional de Blumenau (FURB) - Blumenau (SC), Brasil.

${ }^{3}$ Doutor em Engenharia Ambiental e Sanitária. Professor do Departamento de Engenharia de Produção e Design e do Programa de Pós-graduação em Engenharia Ambiental no Centro de Ciências Tecnológicas da FURB - Blumenau (SC), Brasil.

Endereço para correspondência: Júnia Schultz - Avenida Carlos Chagas Filho, 373 - Ilha do Fundão - 21941-902 - Rio de Janeiro (RJ), Brasil - E-mail: juniaschultz@gmail.com Recebido em: 21/01/2015 - Aceito em: 06/01/2017 - Reg. ABES: 145106 
metabolismo dos micro-organismos, uma vez que cada espécie possui um desenvolvimento ótimo em determinada faixa de temperatura (CHERNICHARO, 2007).

Relata-se que variações na temperatura provocam mudanças no interior do reator, uma vez que alguns grupos microbianos irão tolerar a mudança, enquanto outros não sobreviverão, resultando tanto na alteração dos produtos como na eficiência da remoção de matéria orgânica e na produção de biogás. Porém, poucos estudos têm abordado esse tema (LEW et al., 2011; JEONG et al., 2014; LI et al., 2014).

Nesse contexto, o presente estudo buscou contribuir para a discussão do efeito de diferentes temperaturas no UASB tratando especificamente lodo têxtil, em virtude da necessidade nesse campo. O cenário de informações escassas motivou a realização da pesquisa, visto que o setor têxtil se destaca na indústria mundial e, ao mesmo tempo, é considerado uma atividade altamente poluidora, seja pelo alto consumo de água e energia, seja pela geração de grande volume de resíduos, efluentes e subprodutos ricos em matéria orgânica (IMMICH; SOUZA; SOUZA, 2009; RESENDE, 2012; SCHNEIDERS, 2013).

Diante dessas colocações, objetivou-se avaliar, em escala laboratorial, o comportamento do reator UASB em diferentes condições de temperatura no tratamento de lodo têxtil e produção de biogás.

\section{METODOLOGIA}

\section{Dispositivo experimental e operação}

O reator UASB em escala laboratorial foi construído em aço inox AISI 304, com alimentação por bombeamento de $100 \%$ de lodo biológico, oriundo de uma indústria têxtil sem etapa de tinturaria. $\mathrm{O}$ aparato experimental possui $100 \mathrm{~cm}$ de altura, $12,3 \mathrm{~cm}$ de diâmetro interno e $12 \mathrm{~L}$ de volume, conforme observado na Figura 1.

O estudo foi dividido em três fases, mantendo o tempo de detenção hidráulica (TDH) igual a $24 \mathrm{~h}$ e variando a temperatura.

$\mathrm{Na}$ primeira fase, o objetivo foi avaliar o comportamento do reator à temperatura de $35 \pm 2^{\circ} \mathrm{C}$ (mesofílica), permanecendo nessa condição por 75 dias.

Na segunda fase, houve o aumento gradativo da temperatura e, no trigésimo dia, alcançou-se $45 \pm 2^{\circ} \mathrm{C}$ (termofílica), continuando assim por 95 dias.

A terceira fase consistiu no aumento gradativo da temperatura até $55 \pm 2^{\circ} \mathrm{C}$ (termofílica), permanecendo nessa condição por 96 dias.

Ao todo, foram 326 dias de monitoramento, de $1^{\circ}$ de março de 2013 a 20 janeiro de 2014.

\section{Análises físico-químicas}

Para avaliar a tratabilidade e a influência das alterações de temperatura sobre o tratamento e a produção e composição do biogás, adotou-se um programa de monitoramento do reator com o acompanhamento dos parâmetros apresentados no Quadro 1, realizado em duplicata.

Para a análise da eficiência de remoção dos parâmetros demanda química de oxigênio (DQO), demanda bioquímica de oxigênio (DBO), sólidos totais (ST), sólidos totais voláteis (STV), fósforo total (P-total) e nitrogênio total (N-total), utilizou-se a Equação 1:

$E_{f} R=\frac{\left(S_{0}-S\right)}{S_{0}} * 100$

Em que:

$\mathrm{E}_{\mathrm{f}} \mathrm{R}=$ eficiência de remoção (\%);

$\mathrm{S}_{0}=$ concentração afluente;

$\mathrm{S}=$ concentração efluente.

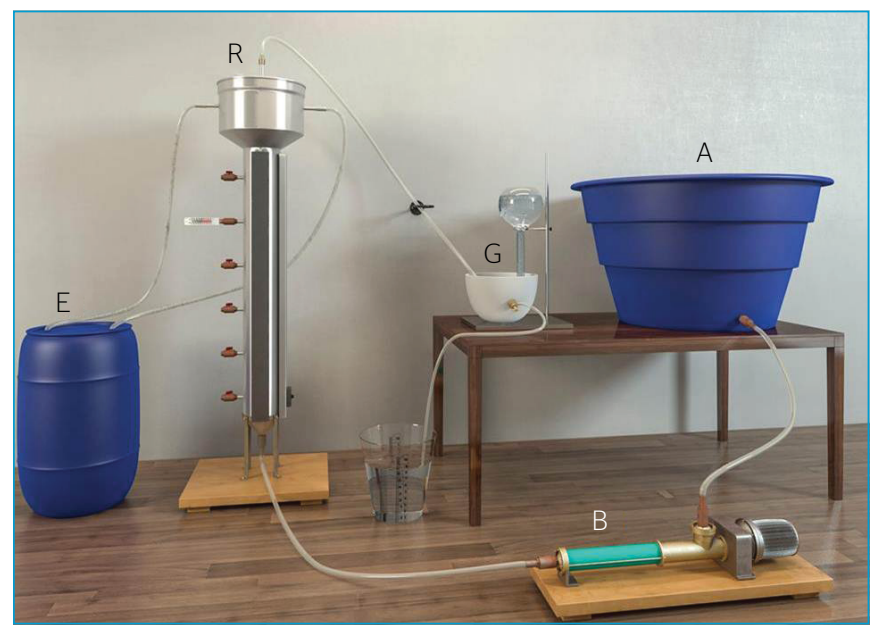

Figura 1 - Representação esquemática do sistema utilizado: A) Afluente - lodo têxtil; B) Bomba helicoidal; R) reator UASB utilizado no experimento; E) Efluente - Iodo tratado; G) Gasômetro - dispositivo utilizado para a medição do volume de biogás produzido.

Quadro 1 - Monitoramento do reator UASB: parâmetros analisados, métodos laboratoriais e frequência das análises realizadas com as amostras coletadas no experimento.

\begin{tabular}{|c|c|c|c|}
\hline \multirow{2}{*}{ Parâmetros } & \multirow{2}{*}{ Método analítico } & \multicolumn{2}{|c|}{ Frequência de amostragem } \\
\hline & & Afluente & Efluente \\
\hline $\mathrm{pH}$ & $\begin{array}{l}\text { Potenciométrico } \\
\left(\mathrm{SM}^{*} 2.310-\mathrm{B}\right)\end{array}$ & Diária & Diária \\
\hline AT e AVT & $\begin{array}{c}\text { Titulométrico } \\
\text { (SM 2.310-B e 5.560-C) }\end{array}$ & Semanal & Semanal \\
\hline DQO & $\begin{array}{l}\text { Colorimétrico em refluxo } \\
\text { fechado (Hexis no 8.000) }\end{array}$ & Semanal & Semanal \\
\hline $\mathrm{DBO}_{5,20^{\circ} \mathrm{C}}$ & Respirométrico $\left(\mathrm{Hach}^{\oplus}\right)$ & Semanal & Semanal \\
\hline $\begin{array}{l}\text { ST, STF e } \\
\text { STV }\end{array}$ & $\begin{array}{c}\text { Gravimétrico } \\
\text { (SM 2.540-B e 2.540-E) }\end{array}$ & Semanal & Semanal \\
\hline $\begin{array}{l}\text { P-total e } \\
\text { N-total }\end{array}$ & $\begin{array}{c}\text { Colorimétrico } \\
\text { (Hexis no } 10.127 \text { e 10.072) }\end{array}$ & Quinzenal & Quinzenal \\
\hline
\end{tabular}

pH: potencial hidrogeniônico; AT: alcalinidade total; AVT: ácidos voláteis totais; DQO: demanda química de oxigênio; DBO: demanda bioquímica de oxigênio;

ST: sólidos totais; STF: sólidos totais fixos; STV: sólidos totais voláteis; P-total: fósforo total; N-total: nitrogênio total; *SM: standard methods - APHA; AWWA; WEF (2012). 
A produção do biogás no sistema foi determinada diariamente pelo método volumétrico com deslocamento de água. Sua caracterização foi mensurada semanalmente utilizando-se o analisador de gases portátil GEM 2000 (Landtec ${ }^{\circledR}$ ), quantificando-se a concentração de metano, gás carbônico, oxigênio e balance gas (BAL) - que consiste na somatória de outros gases presentes na amostra.

\section{Análise estatística}

Os valores médios e o desvio padrão dos parâmetros analisados foram submetidos à análise de variância (ANOVA) e, posteriormente, ao teste de Tukey, a 5\% de significância, utilizando-se o software Statistica 7.0. Os cálculos e as representações gráficas foram realizados com o editor de planilhas Microsoft Excel ${ }^{\circledR} 2007$.

\section{RESULTADOS E DISCUSSÃO}

Os resultados encontrados nos parâmetros $\mathrm{pH}$, alcalinidade total (AT) e ácidos voláteis totais (AVT) podem ser observados na Tabela 1.

Em todas as fases de monitoramento, os valores médios do $\mathrm{pH}$ afluente ficaram próximos de 7,0, resultado que se deve à correção do mesmo com solução ácida $\left(\mathrm{H}_{2} \mathrm{SO}_{4}\right.$ a $\left.10 \%\right)$, realizada a fim de fornecer condições ótimas para a degradação microbiana. O mesmo ajuste foi adotado em diversos estudos, como os realizados por Bueno (2010) e Schneiders (2013). Esse cuidado se deve ao fato de as Arqueas metanogênicas, principal grupo responsável pela degradação do material orgânico, serem sensíveis a alterações no $\mathrm{pH}$, sendo que seu crescimento ótimo se encontra entre o pH 6,8 e o pH 7,4 (CHERNICHARO, 2007).

No efluente, os valores médios do $\mathrm{pH}$ ficaram acima dos valores médios do $\mathrm{pH}$ afluente nas três fases de monitoramento. Esse fenômeno se deu pelo efeito tampão originado a partir da elevada alcalinidade produzida no reator UASB, mostrando que o mesmo operou de forma estável durante todo o período experimental (PEREIRA; CAMPOS; MOTTERAN, 2013).

A AT apresentou valores inferiores aos do efluente nas fases monitoradas, o que, segundo Barbosa, Botari e Freire (2009), se dá pelo aumento da concentração de alcalinidade do substrato ao passar pelo processo de digestão aneróbia no interior do reator. Esse mesmo comportamento foi constatado por Pereira, Campos e Moterani (2010) ao avaliarem o desempenho de um reator UASB em escala piloto no tratamento de efluentes de suinocultura, em que a concentração média da AT foi de 1,383 mg. $\mathrm{L}^{-1}$ no afluente e de 1,442 mg. $\mathrm{L}^{-1}$ no efluente. Rodrigues et al. (2010) observaram a mesma situação ao avaliarem o tratamento de efluente da suinocultura em UASB, encontrando $3,1 \mathrm{~g} . \mathrm{L}^{-1}$ de AT no afluente e 3,7 g.L $\mathrm{L}^{-1}$ no efluente.

Sobre os AVT, observou-se decréscimo da concentração média do afluente para o efluente, o que pode ser explicado por sua neutralização ao longo do tratamento do substrato no reator UASB (BARBOSA; BOTARI; FREIRE, 2009; RODRIGUES et al., 2010). É importante pontuar que, conforme citado por Silva e Nour (2005), o equilíbrio na concentração dos AVT é um bom indicador do funcionamento adequado do reator UASB, sendo importante no acompanhamento da atividade das bactérias acidogênicas e Arqueas metanogênicas, pois a inibição do processo anaeróbio por AVT está associada ao $\mathrm{pH}$, e baixos valores de $\mathrm{pH}$ geralmente estão relacionados a altas concentrações de AVT, mostrando a falência do processo.

Metcalf e Eddy (2003) salientam que, para o processo de digestão anaeróbia ocorrer de maneira satisfatória, a alcalinidade deve estar entre 1,000 e 5,000 mg. $\mathrm{L}^{-1}$, enquanto a concentração dos AVT deve ser menor que $250 \mathrm{mg} . \mathrm{L}^{-1}$, com uma relação AVT/AT inferior a 0,30.

A partir dos dados observados na Tabela 1, constata-se que os valores médios encontram-se dentro do preconizado pela literatura e que a relação AVT/AT foi de 0,08, 0,05 e 0,05 para as fases 1, 2 e 3, respectivamente. Esses resultados, visualizados em conjunto com os valores de $\mathrm{pH}$, indicam que o sistema apresentou estabilidade e capacidade de tamponamento do reator UASB, não permitindo o acúmulo de ácidos voláteis no decorrer das três fases de operação, o que seria prejudicial.

Na Tabela 2 observa-se a performance do reator em cada fase de operação, com base nos parâmetros DQO, DBO bruta, sólidos e nutrientes.

Quanto ao parâmetro DQO, houve diferença significativa entre os valores encontrados no afluente e no efluente nas três fases de

Tabela 1 - Valores médios e desvio padrão de pH, alcalinidade total e ácidos voláteis totais do afluente e do efluente durante as fases 1,2 e 3 de operação do reator.

\begin{tabular}{|c|c|c|c|c|}
\hline Parâmetros & Amostra & Fase 1 & Fase 2 & Fase 3 \\
\hline \multirow{2}{*}{$\mathrm{pH}$} & Afluente & $7,05 \pm 0,14 \mathrm{~B} \mathrm{a}$ & $7,02 \pm 0,07 \mathrm{~B} \mathrm{a}$ & $7,04 \pm 0,16 \mathrm{~B} \mathrm{a}$ \\
\hline & Efluente & $7,80 \pm 0,36 \mathrm{~A} \mathrm{~b}$ & $8,17 \pm 0,40 \mathrm{~A} a$ & $8,23 \pm 0,25 \mathrm{~A} \mathrm{a}$ \\
\hline $\mathrm{AT}\left(\mathrm{mgCaCO}_{3} \mathrm{~L}^{-1}\right)$ & Efluente & $1389,36 \pm 421,82 \mathrm{~A} b$ & $2230,88 \pm 266,92 \mathrm{~A} \mathrm{a}$ & $2190,71 \pm 321,55 \mathrm{~A} \mathrm{a}$ \\
\hline AVT $\left(m g . L^{-1}\right)$ & Afluente & $203,99 \pm 62,60 \mathrm{~A} \mathrm{a}$ & $147,42 \pm 49,46$ A b & $141,50 \pm 39,28 \mathrm{~A} \mathrm{~b}$ \\
\hline
\end{tabular}

Médias seguidas da mesma letra, minúscula na linha e maiúscula na coluna, não diferem entre si pelo teste de Tukey (5\%); pH: potencial hidrogeniônico; AT: alcalinidade total; AVT: ácidos voláteis totais. 
monitoramento, sendo expressivamente menores no efluente, com remoção média da matéria orgânica de $96 \%$, na fase 1, e de $97 \%$, nas fases 2 e 3 (Figura 2).

Khemkhao et al. (2012) observaram o mesmo resultado ao tratar efluente óleo de palma em reator UASB, que, em temperaturas termofílicas, apresentou as maiores taxas de remoção, com $85,9 \%$ a $52^{\circ} \mathrm{C} \mathrm{e}$ $83,5 \%$ a $37^{\circ} \mathrm{C}$. Outro estudo, comparando a eficiência de remoção de DQO em reator UASB em temperaturas mesofílicas e termofílicas, foi desenvolvido por Jeong et al. (2014), tratando efluente óleo de palma, obtendo remoção de $90-93 \%$ em temperatura mesofílica e 93-95\% em temperatura termofílica. Relata-se também que os reatores anaeróbios em temperatura termofílica promoveriam maior remoção da fração orgânica do substrato em comparação aos reatores mesofílicos (RAMAKRISHNAN; SURAMPALLI, 2012). No presente estudo, porém, não houve diferença estatística entre as fases com temperatura mesofílica e termofílica.

Tabela 2 - Valores médios e desvio padrão dos parâmetros físico-químicos do afluente e do efluente durante as fases 1, 2 e 3 de operação do reator.

\begin{tabular}{|c|c|c|c|c|}
\hline Parâmetros & Amostra & Fase 1 & Fase 2 & Fase 3 \\
\hline \multirow{2}{*}{$\mathrm{DQO}\left(\mathrm{mg} \cdot \mathrm{L}^{-1}\right)$} & Afluente & $14219,00 \pm 6878,45 \mathrm{~A} \mathrm{a}$ & $17714,38 \pm 7150,15 \mathrm{~A} \mathrm{a}$ & $13561,62 \pm 3912,21 \mathrm{~A} \mathrm{a}$ \\
\hline & Efluente & $356,70 \pm 122,59 \mathrm{~B} b$ & $599,56 \pm 197,71 \mathrm{~B} \mathrm{a}$ & $689,35 \pm 114,55 \mathrm{~B} \mathrm{a}$ \\
\hline \multirow{2}{*}{$\mathrm{DBO}\left(\mathrm{mg} \cdot \mathrm{L}^{-1}\right)$} & Afluente & $2146,96 \pm 780,65 \mathrm{~A} \mathrm{a}$ & $2193,0 \pm 356,2 \mathrm{~A} \mathrm{a}$ & $2039,00 \pm 696,39$ А а \\
\hline & Efluente & $345,08 \pm 145,15$ B b & $106,80 \pm 69,18$ В а & $120,00 \pm 66,88 \mathrm{~B} \mathrm{a}$ \\
\hline \multirow{2}{*}{$\mathrm{ST}\left(\mathrm{g} \cdot \mathrm{L}^{-1}\right)$} & Afluente & $16,31 \pm 2,42 \mathrm{~A} \mathrm{a}$ & $15,61 \pm 2,26 \mathrm{~A} \mathrm{a}$ & $16,02 \pm 2,30 \mathrm{~A} \mathrm{a}$ \\
\hline & Efluente & $2,98 \pm 0,88 \mathrm{~B} \mathrm{a}$ & $2,69 \pm 1,62 \mathrm{~B} \mathrm{a}$ & $2,74 \pm 1,22 \mathrm{~B} \mathrm{a}$ \\
\hline \multirow{2}{*}{$\operatorname{STV}\left(g . L^{-1}\right)$} & Afluente & $11,12 \pm 1,81 \mathrm{~A} \mathrm{a}$ & $13,47 \pm 1,47 \mathrm{~A} \mathrm{a}$ & $13,98 \pm 1,44 \mathrm{~A} a$ \\
\hline & Efluente & $1,54 \pm 0,80 \mathrm{~B} \mathrm{a}$ & 1,70 $\pm 0,65 \mathrm{~B} \mathrm{a}$ & $1,68 \pm 0,77 \mathrm{~B} \mathrm{a}$ \\
\hline \multirow{2}{*}{ P-total (mg. $\left.L^{-1}\right)$} & Afluente & $958,08 \pm 217,61 \mathrm{~A}$ a & $946,0 \pm 233,2 \mathrm{~A} \mathrm{a}$ & $1001,0 \pm 296,3 \mathrm{~A} \mathrm{a}$ \\
\hline & Efluente & $132,98 \pm 25,91 \mathrm{~B} b$ & $51,00 \pm 19,81 \mathrm{~B} \mathrm{a}$ & $52,30 \pm 15,92 \mathrm{~B} \mathrm{a}$ \\
\hline \multirow{2}{*}{$\mathrm{N}$-total $\left(\mathrm{mg} \cdot \mathrm{L}^{-1}\right)$} & Afluente & $1536,25 \pm 995,93 \mathrm{~A} \mathrm{a}$ & $1045,00 \pm 176,78 \mathrm{~A} \mathrm{~b}$ & $1197,5 \pm 184,8$ A b \\
\hline & Efluente & $160,41 \pm 15,26$ B b & $67,00 \pm 19,09 \mathrm{~B} \mathrm{a}$ & $71,13 \pm 10,90 \mathrm{~B} \mathrm{a}$ \\
\hline
\end{tabular}

Médias seguidas da mesma letra, minúscula na linha e maiúscula na coluna, não diferem entre si pelo teste de Tukey (5\%); DQO: demanda química de oxigênio; DBO: demanda bioquímica de oxigênio; ST: sólidos totais; STV: sólidos totais voláteis; P-total: fósforo total; N-total: nitrogênio total.

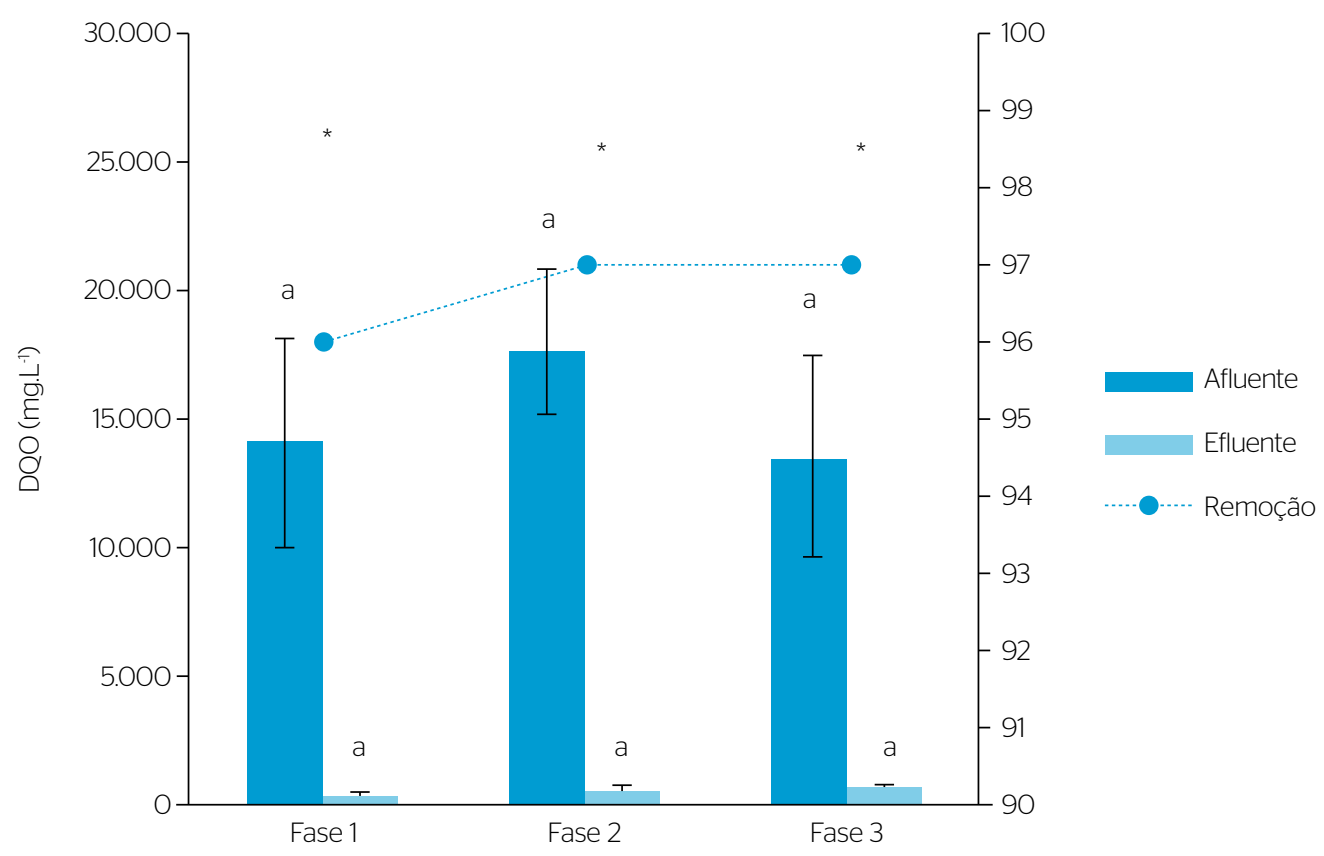

Médias seguidas da mesma letra não diferem entre si pelo teste de Tukey $(p<0,05)$, entre as fases; DQO: demanda química de oxigênio; *Diferença estatística dos valores de afluente e efluente pelo teste de Tukey $(p<0,05)$

Figura 2 - Valores médios, desvio padrão e eficiência de remoção (\%) do parâmetro demanda química de oxigênio ao longo das três fases de experimentação. 
A remoção da carga de DBO em sistemas de tratamento de resíduos industriais é tida como o principal parâmetro no Brasil (HAMERSKI, 2012), e esse parâmetro também apresentou maior remoção nas fases com temperatura termofílica - na fase 2 teve $95 \%$ e na fase $3,94 \%$ enquanto na fase 1 (mesofílica) observaram-se apenas $84 \%$, sendo significativamente inferior às demais fases (Figura 3 ).

Dados semelhantes de remoção de DBO foram encontrados por Pinto et al. (2014), que avaliaram o desempenho do reator UASB no tratamento de águas residuárias da suinocultura, conseguindo remoção de $86,5 \%$ da DBO afluente. Rodrigues et al. (2010) trataram o mesmo resíduo em UASB, atingindo remoção de $87 \%$. Quanto aos valores observados nas fases termofílicas da presente pesquisa ( 94 e 95\% de remoção), estes indicaram ótimo desempenho do reator UASB ante o tratamento do lodo biológico têxtil, especialmente quando relacionados aos comumente relatados na literatura, situando-se entre 70 e 90\% (CHERNICHARO, 2007).

As concentrações médias de ST e STV evidenciaram que estes também apresentaram diminuição significativa do afluente para o efluente em todas as fases de experimentação. Por meio do cálculo de remoção, as fases termofílicas ( 2 e 3 ) obtiveram os melhores resultados tanto para ST quanto para STV. A fase 3 apresentou remoção de $86 \%$ de ST e $93 \%$ de STV; a fase 2, 85 e $93 \%$; e a fase 1,83 e $91 \%$.

Resultados similares foram obtidos por Schneiders (2013) que, tratando lodo têxtil em reator UASB em escala laboratorial a $33^{\circ} \mathrm{C}$, observou remoção de $89 \%$ para ST e $94 \%$ para STV. As taxas encontradas no presente estudo foram superiores às de Leite (2011), que observou remoções de ST entre 7,2 e 63,0\% e de STV entre 15,4 e 67,0\% na digestão anaeróbia mesofílica de lodo adensado de uma estação de tratamento de esgoto (ETE) em um digestor piloto. Os valores encontrados também foram superiores aos observados no estudo de Zahedi et al. (2013), em que a maior remoção foi de $69 \%$ de STV ao tratar resíduos sólidos urbanos industriais em reator anaeróbio de tanque agitado contínuo.

A partir dos resultados observados, atrelados a dados encontrados na literatura, verifica-se que o reator UASB apresentou boa performance no tratamento do lodo nas diferentes fases de operação, atuando na remoção da matéria orgânica presente no substrato.

Pode-se observar na Figura 4 os valores médios e as taxas de remoção dos nutrientes P-total e N-total, que se mostraram significativamente inferiores no efluente, com eficiência de remoção de P-total do sistema de $95 \%$ nas fases 2 e 3 e de $86 \%$ na fase 1 , enquanto no $\mathrm{N}$-total foi observada redução de $94 \%$ nas fases 2 e 3 e de apenas $89 \%$ na fase 1 .

Mesmo não sendo dimensionados primariamente para a remoção de nutrientes, os reatores UASB podem fazê-lo, como salientam Oliveira e Von Sperling (2005), porém alcançando baixas remoções, em torno de $35 \%$ para fósforo e $60 \%$ para nitrogênio, valores menores do que os alcançados no presente estudo.

A redução nas concentrações de fósforo e as elevadas taxas de eficiência de remoção de P-total no reator UASB, em todas as fases de experimentação, podem ser atribuídas à retenção de sólidos no lodo do reator (DENG et al., 2008) e à possibilidade de remoção por precipitação do fósforo, fenômeno observado por Duda e Oliveira (2011) ao avaliarem o tratamento de águas residuárias da suinocultura em UASB, constatando reduções significativas de P-total do afluente para o efluente (42 a 68\%). Para N-total, a retenção do nutriente na biomassa do reator e sua assimilação pelos micro-organismos existentes no UASB podem ter contribuído

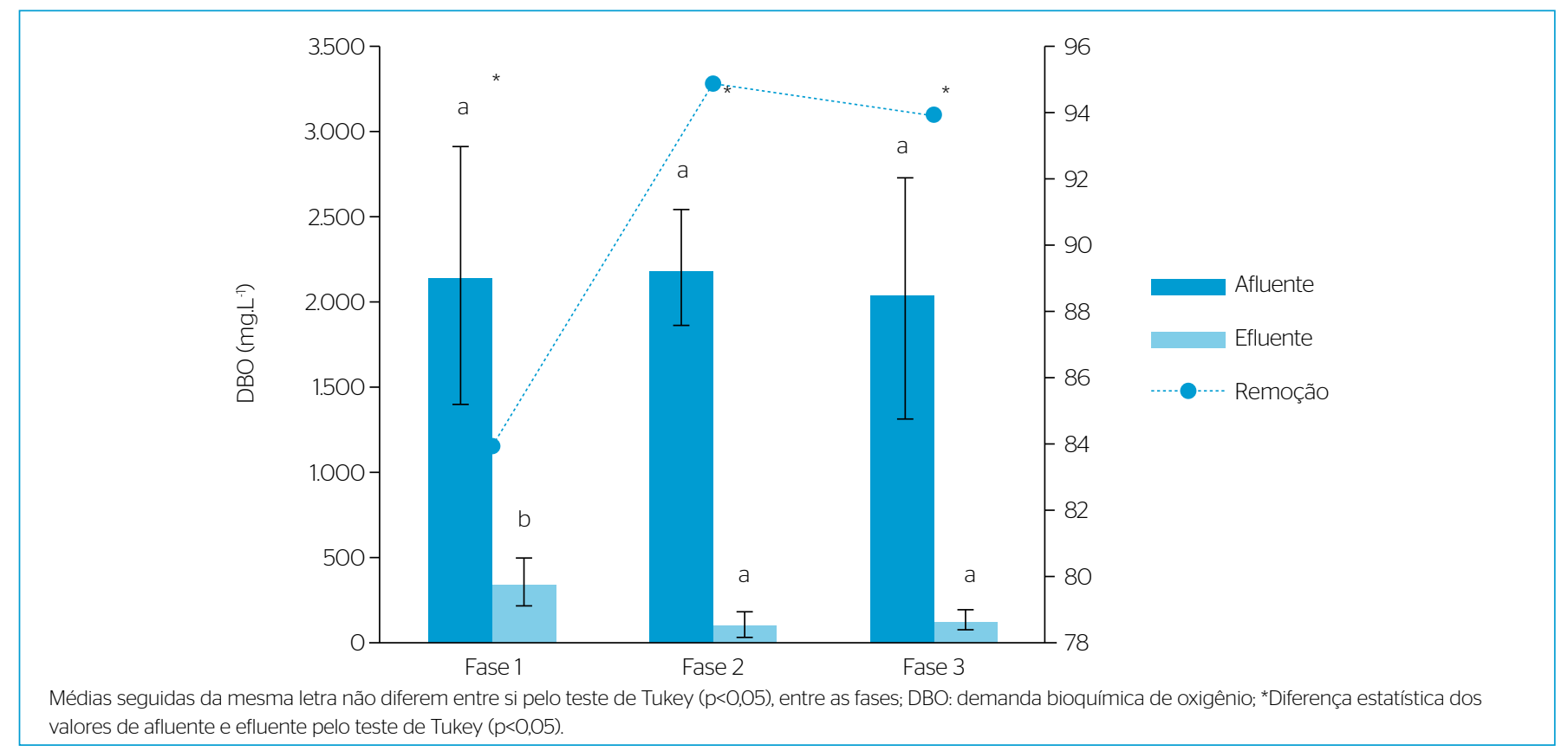

Figura 3 - Valores médios, desvio padrão e eficiência de remoção (\%) do parâmetro demanda química de oxigênio ao longo das três fases de experimentação. 
para as altas taxas de remoção, uma vez que essas bactérias utilizam nitrogênio para a síntese de aminoácidos, proteínas, bases nitrogenadas, hormônios e outras moléculas (ASSUNÇÃO; VON SPERLING, 2012). Santos e Oliveira (2011) e Gadelha (2011) mencionaram e observaram o mesmo comportamento em reatores UASB tratando águas residuárias da suinocultura e domésticas, respectivamente.

Durante o monitoramento do sistema, especificamente na temperatura mesofílica, houve arraste de sólidos gerando lodo de excesso, que flotava e se acumulava na parte superior do reator, exigindo o descarte contínuo do mesmo, perfazendo ao total 75 descartes e um volume de $102 \mathrm{~L}$. Porém, a partir do incremento de temperatura para $45^{\circ} \mathrm{C}$, não houve mais formação de lodo de excesso, condição que se manteve até a fase 3 do experimento, a $55^{\circ} \mathrm{C}$.
Quanto à produção de biogás, constatou-se que o menor valor foi encontrado na fase 1 , com média de $0,66 \mathrm{~L} \cdot \mathrm{d}^{-1}$, diferindo estatisticamente das fases 2 e 3, que apresentaram médias de 1,48 e $1,28 \mathrm{~L}^{\mathrm{d}} \mathrm{d}^{-1}$, respectivamente. Vale ressaltar que, nos períodos de transição gradual entre as temperaturas de 35 a $45^{\circ} \mathrm{C}$ e de 45 a $55^{\circ} \mathrm{C}$, a produção do biogás atingiu os níveis mais elevados, com médias de 3,44 e 1,63 L.d ${ }^{-1}$, respectivamente. O volume total de biogás produzido durante o período de monitoramento foi de 465,1 L (Figura 5 e Tabela 3).

O aumento da temperatura de mesofílica para termofílica teve o objetivo de otimizar a produção de biogás, o que foi observado. Com o incremento do parâmetro temperatura, houve um aumento de $112,1 \%$ da fase 1 para a fase 2 e de $97 \%$ da fase 1 para a fase 3 (Tabela 3 ).

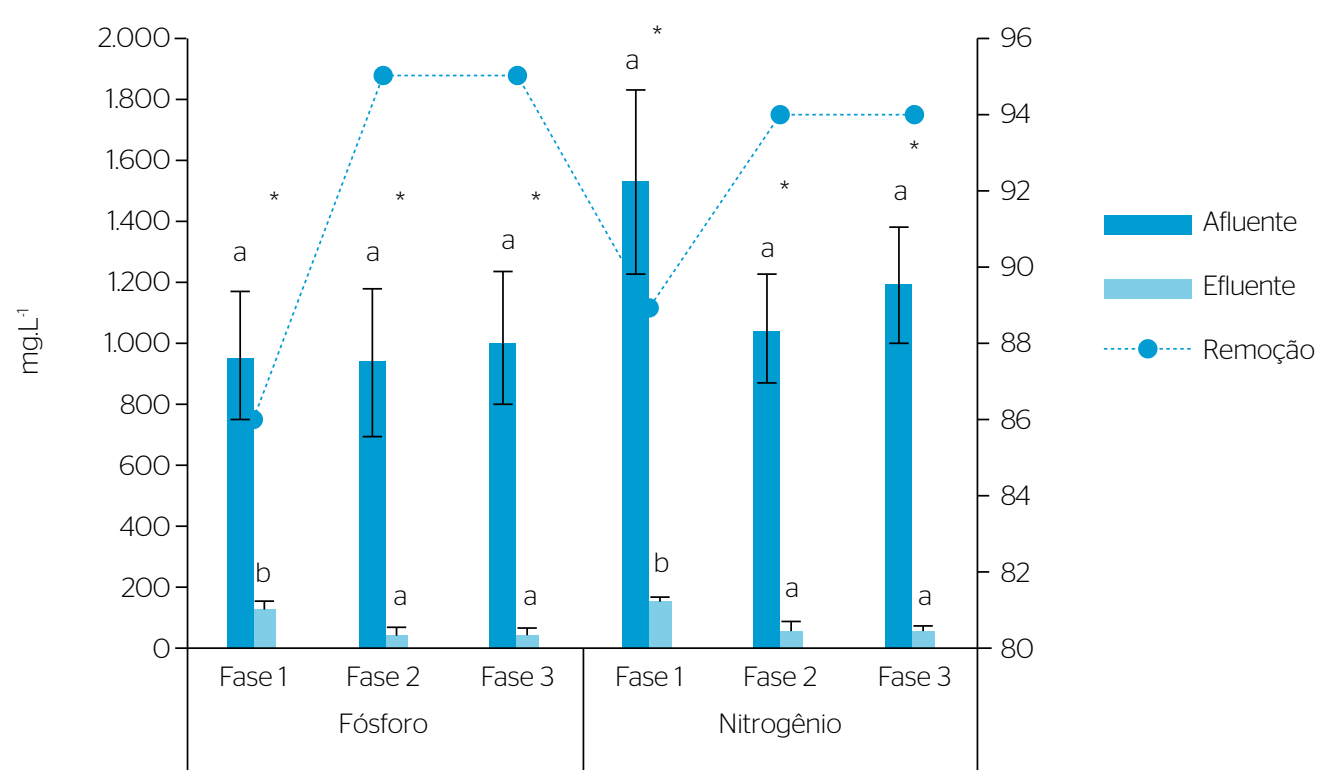

Médias seguidas da mesma letra não diferem entre si pelo teste de Tukey $(p<0,05)$, entre as fases.

*Diferença estatística dos valores de afluente e efluente pelo teste de Tukey $(p<0,05)$.

Figura 4 - Valores médios, desvio padrão e eficiência de remoção (\%) dos nutrientes fósforo e nitrogênio total nas três fases de experimentação.

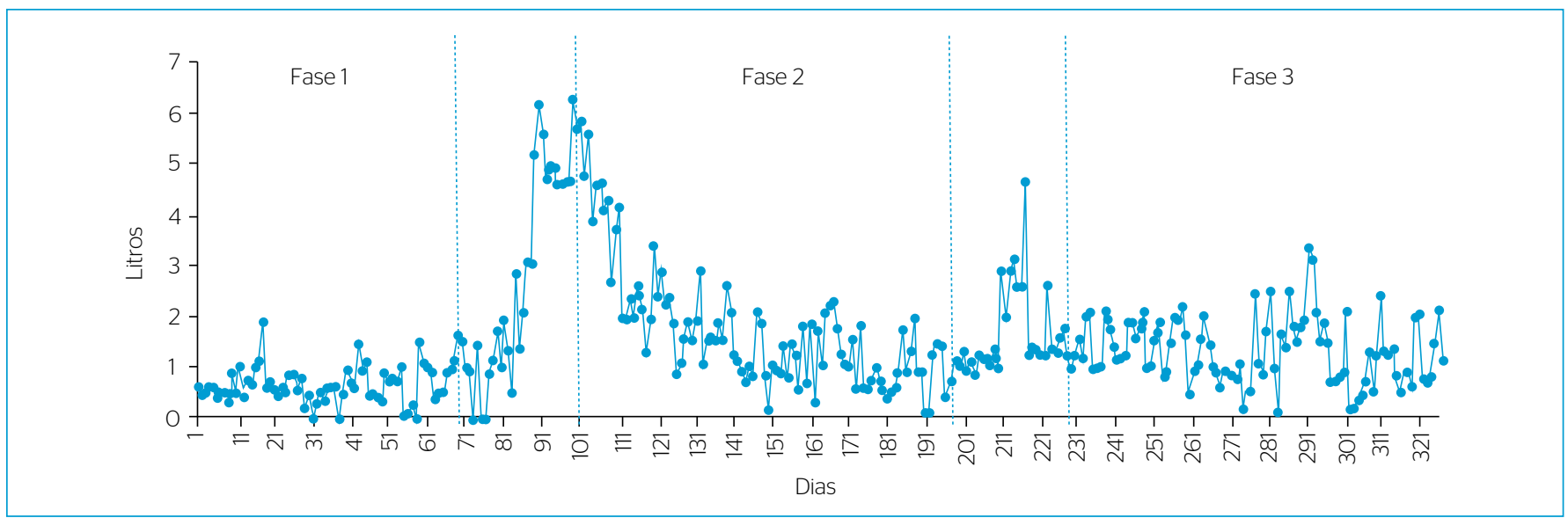

Figura 5 - Vazão do biogás produzido no monitoramento do reator UASB ao longo das três fases do experimento. 
Tabela 3 - Comparação da produção do biogás com a concentração de metano no biogás nas três fases do experimento.

\begin{tabular}{|c|c|c|c|}
\hline Biogás & $\begin{array}{l}\text { Fase } 1-35^{\circ} \mathrm{C} \\
\text { (Média } \pm \mathrm{DP} \text { ) }\end{array}$ & $\begin{array}{l}\text { Fase } 2-45^{\circ} \mathrm{C} \\
\text { (Média } \pm \mathrm{DP} \text { ) }\end{array}$ & $\begin{array}{l}\text { Fase } 3-55^{\circ} \mathrm{C} \\
\text { (Média } \pm \mathrm{DP} \text { ) }\end{array}$ \\
\hline $\begin{array}{l}\text { Vazão da produção } \\
\text { (L.d-1') }\end{array}$ & $0,66 \pm 0,38 \mathrm{~b}$ & $1,48 \pm 0,89 \mathrm{a}$ & $1,28 \pm 0,62 \mathrm{a}$ \\
\hline $\begin{array}{l}\text { Porcentagem de } \\
\text { metano (\%) }\end{array}$ & $27,3 \pm 1,4 \mathrm{c}$ & $36,7 \pm 0,9 \mathrm{a}$ & $33,2 \pm 1,1 \mathrm{~b}$ \\
\hline
\end{tabular}

DP: desvio padrão.

Médias seguidas da mesma letra não diferem estatisticamente entre si pelo teste de Tukey $(p<0,05)$.

Os resultados corroboram o citado por Weiss et al. (2009), segundo os quais operações em condições termofílicas geralmente apresentam maior produção de biogás. Nges e Liu (2010) observaram o mesmo fenômeno ao trabalhar com lodo de esgoto em reator de tanque agitado contínuo, com produção média de 2,32 L em temperatura termofílica e 2,14 L em mesofílica.

Quanto à composição do biogás, verificou-se maior porcentagem de metano na temperatura de $45^{\circ} \mathrm{C}$, com média de $36,7 \%$, sendo significativamente maior que a $55^{\circ} \mathrm{C}(33,2 \%)$ e a $35^{\circ} \mathrm{C}(24,3 \%)$ (Tabela 3$)$.

O decréscimo na porcentagem de metano a $55^{\circ} \mathrm{C}$ pode ser explicado pela redução da biomassa metanogênica no reator UASB, uma vez que ela é sensível a elevadas temperaturas, fato que Khemkhao et al. (2012) verificaram por meio do teste molecular eletroforese em gel de gradiente desnaturante (DGGE), observando que a $57^{\circ} \mathrm{C}$ a composição desses micro-organismos sofreu baixa significativa. O mesmo comportamento foi relatado por Li et al. (2014) ao avaliarem a comunidade microbiana $\mathrm{e}$ a performance de um reator anaeróbio híbrido no tratamento do efluente ácido tereftálico (PTA) em temperaturas de 33 a $52^{\circ} \mathrm{C}$. Nas temperaturas mais altas, houve queda da comunidade metanogênica, o que também foi observado por Tähti, Kaparaju e Rintala (2013).

\section{CONCLUSÃO}

A partir dos resultados, concluiu-se que:

- O reator apresentou desempenho estável e ótima performance na remoção de todos os parâmetros físico-químicos analisados.

- O tratamento foi influenciado positivamente pelo incremento da temperatura, uma vez que houve maiores remoções de DQO, DBO bruta e nutrientes (P-total e $\mathrm{N}$-total) nas temperaturas termofílicas.

- Observaram-se maior produção de biogás e maior concentração de metano na fase $2\left(45^{\circ} \mathrm{C}\right.$ - termofílica).

- Sob temperaturas termofílicas, não houve produção de lodo de excesso, não havendo necessidade de pós-tratamento ou descarte em aterro.

Com as conclusões obtidas no presente estudo, pode-se confirmar a tratabilidade do lodo têxtil em reator UASB (escala laboratorial) e estabelecer que, para o tratamento, bem como para a produção de biogás e metano, a temperatura indicada é de $45^{\circ} \mathrm{C}$ em um TDH de $24 \mathrm{~h}$.

\section{REFERÊNCIAS}

AMERICAN PUBLIC HEALTH ASSOCIATION (APHA); AMERICAN WATER WORKS ASSOCIATION (AWWA); WATER ENVIRONMENTAL FEDERATION (WEF). (2O12) Standard methods for the examination of water and wastewater. 22. ed. Washington, D.C.: APHA; AWWA; WEF. 1496 p.

ASSUNÇÃO, F.A.L.; VON SPERLING, M. (2012) Importance of the ammonia volatilization rates in shallow maturation ponds treating UASB reactor effluent. Water Science and Technology, v. 66, p. $1239-1246$.

BARBOSA, A.F.; BOTARI, A.; FREIRE, F.B. (2009) Análise do tratamento de água residuária sintética em reator UASB seguido de filtro preenchido com solo natural. Revista Tecnológica, v. 18, p. 53-67.

BUENO, R.F. (2010) Comparação entre biodigestores operados em escala piloto para produção de biogás alimentado com estrume bovino. Holos Environment, v. 10, n. 1, p. 111-125.

CHERNICHARO, C.A.L. (2007) Reatores anaeróbios. Belo Horizonte: Departamento de Engenharia Sanitária e Ambiental, Universidade Federal de Minas Gerais. 379 p.
DENG, L.W.; ZHENG, P.; CHEN, Z.A.; MAHMOOD, Q. (2008) Improvement in post-treatment of digested swine wastewater. Bioresource Technology, Barking, v. 99, n. 8, p. 3136-3145.

DUDA, R.M.; OLIVEIRA, R.A. (2011) Tratamento de águas residuárias de suinocultura em reator UASB e filtro anaeróbio em série seguidos de filtro biológico percolador. Engenharia Sanitária \& Ambiental, v. 16, p. 91-100

FERNANDES, D.M.; COSTANZI, R.N.; FEIDEN, A.; SOUZA, S.N.M.; KITAMURA, D.S. (2014) Processo de biodigestão anaeróbia em uma granja de suínos. Ambiência, v. 10, n. 3, p. 741-754.

GADELHA, D.A.C. (2011) Variação de compostos nitrogenados em efluentes de refinárias de petróleo tratados em reator UASB em forma de "Y". In: SIMPÓSIO BRASILEIRO DE RECURSOS HÍDRICOS, 19., 2011. Anais... Maceió: RBRH.

GARCIA, J.N.V.M. (2011) Análise de sustentabilidade de sistemas de digestão anaeróbia. 88f. Dissertação (Mestrado) - Programa de PósGraduação em Sistemas Energéticos Sustentáveis, Universidade de Aveiro, Aveiro. 
HAMERSKI, F. (2012) Partida de um reator anaeróbio de fluxo ascendente com manta de lodo (UASB) no tratamento de efluentes provenientes de uma indústria de laticínios. 77f. Dissertação (Mestrado) - Programa de Pós-Graduação em Engenharia de Processos, Universidade Federal de Santa Maria, Santa Maria.

IMMICH, A.P.S.; SOUZA, A.A.U.; SOUZA, S.M.A. (2009) Adsorption of remazol blue RR from textile effluents using Azadirachta indica leaf powder as an alternative adsorbent. Adsorption Science \& Technology, v. 27, p. 461-478.

JEONG, J.Y.; SON, S.M.; PYON, J.H.; PARK, J.Y. (2O14) Performance comparison between mesophilic and thermophilic anaerobic reactors for treatment of palm oil mill effluent. Bioresource Technology, v. 165, p. 122-128.

KHEMKHAO, M.; NUNTAKUMJORN, B.; TECHKARNJANARUK, S.; PHALAKORNKULE, C. (2012) UASB performance and microbial adaptation during a transition from mesophilic to thermophilic treatment of palm oil mill effluent. Journal of Environmental Management, v. 103, p. 74-82

KIM, D.H.; LIM, W.T.; LEE, M.K.; KIM, M.S. (2012) Effect of temperature on continuous fermentative lactic acid (LA) production and bacterial community, and development of LA-producing UASB reactor. Bioresource Technology, v. 119, p. 355-361.

LEITE, W.R.M. (2011) Digestão anaeróbia mesofílica de lodo adensado de estação de tratamento de esgoto. 142f. Dissertação (Mestrado) - Programa de Pós-graduação em Engenharia Ambiental, Universidade Federal de Santa Catarina, Florianópolis.

LEW, B.; LUSTIG, I.; BELIAVSKI, M.; TARRE, S.; GREEN, M. (2011) An integrated UASB-sludge digester system for raw domestic wastewater treatment in temperate climates. Bioresource Technology, v. 102, p. 4921-4924.

LI, X.K.; MA, K.L.; MENG, L.W.; ZHANG, J.; WANG, K. (2014) Performance and microbial community profiles in an anaerobic reactor treating with simulated PTA wastewater: from mesophilic to thermophilic temperature. Water Research, v. 61, p. 57-66.

METCALF; EDDY. (2003) Wasterwater engineering: treatment, disposal and reuse. 4. ed. New York: McGraw Hill. 823 p.

MOTTERAN, F.; BRAGA, J.K.; SAKAMOTO, I.K.; SILVA, E.L.; VARESCHE, M.B.A. (2014) Degradation of high concentrations of nonionic surfactant (linear alcohol ethoxylate) in an anaerobic fluidized bed reactor. Science of the Total Environment, v. 481, p. 121-128.

NGES, I.A.; LIU, J. (2010) Effects of solid retention time on anaerobic digestion of dewatered-sewage sludge in mesophilic and thermophilic conditions. Renewable Energy, v. 35, p. 2200-2206.

OLIVEIRA, S.M.A.C:; VON SPERLING, M. (2005) Avaliação de 166 ETEs em operação no país, compreendendo diversas tecnologias. Parte 1- Análise de desempenho. Engenharia Sanitária \& Ambiental, v. 10, p. 347-357.

PEREIRA, E.L.; CAMPOS, C.M.M.; MOTERANI, F. (2009) Efeitos do $\mathrm{pH}$, acidez e alcalinidade na microbiota de um reator anaeróbio de manta de lodo (UASB) tratando efluentes de suinocultura. Ambiente \& Água, v. 4, p. 157-168.
PEREIRA, E.L.; CAMPOS, C.M.M.; MOTERANI, F. (2010) Evaluation of physical-chemical performance of an UASB reactor in removing pollutants of pig wastewater. Ambiente \& Água, v. 5, p. 79-88.

PEREIRA, E.L.; CAMPOS, C.M.M.; MOTTERAN, F. (2013) Physicochemical study of $\mathrm{pH}$, alkalinity and total acidity in a system composed of Anaerobic Baffled Reactor in series with Upflow Anaerobic Sludge Blanket reactor in the treatment of pig farming wastewater. Acta Scientiarum Technology, v. 35, p. 477-483.

PINTO, A.C.A.; RODRIGUES, L.S.; OLIVEIRA, P.R.; SPERLING, M.V.; CRISÓSTOMO, C.M.; SILVA, I.J. (2014) Eficiência de lagoas de polimento no pós-tratamento de reator UASB no tratamento de águas residuárias de suinocultura. Arquivo Brasileiro de Medicina Veterinária e Zootecnia, v. 66, n. 2, p. 360-366.

RAMAKRISHNAN, A.; SURAMPALLI, R.Y. (2012) Performance of anaerobic hybrid reactors for the treatment of complex phenolic wastewaters with biogas recirculation. Bioresource Technology, v. 129, p. 26-32.

RESENDE, L.P. (2012) Reúso na indústria têxtil e lavanderias. Hydro, n. 66, p. 14-19.

RODRIGUES, L.S.; SILVA, I.J.; ZOCRATO, M.C.O.; PAPA, D.N.; VON SPERLING, M.; OLIVEIRA, P.R. (2010) Avaliação de desempenho de reator UASB no tratamento de águas residuárias de suinocultura. Revista Brasileira de Engenharia Agrícola Ambiental, v. 14, n. 1, p. $94-100$

SANTOS, A.; OLIVEIRA, R.A. (2011) Tratamento de águas residuárias de suinocultura em reatores anaeróbios horizontais seguidos de reator aeróbio em batelada sequencial. Engenharia Agrícola, v. 31 , n. 4 , p. $781-794$

SCHNEIDERS, D. (2013) Tratamento de lodo têxtil e produção de biogás em reator anaeróbio de fluxo ascendente e manta de lodo (UASB). 111 f. Dissertação (Mestrado) - Programa de Pós-Graduação em Engenharia Ambiental, Fundação Universidade Regional de Blumenau, Blumenau.

SILVA, G.H.R.; NOUR, E.A.A. (2005) Reator compartimentado anaeróbio/aeróbio: Sistema de baixo custo para tratamento de esgotos de pequenas comunidades. Revista Brasileira de Engenharia Agrícola \& Ambiental, v. 9, p. 268-275.

TÄHTI, H.; KAPARAJU, P.; RINTALA, J. (2O13) Hydrogen and methane production in extreme thermophilic conditions in two-stage (upflow anaerobic sludge bed) UASB reactor system. International Journal of Hydrogen Energy, v. 38, p. 4997-5002.

WEISS, A.; JÉRÔME, V.; BURGHARDT, D.; LIKKE, L.; PEIFFER, S.; HOFSTETTER, E.M.; GABLER, R.; FREITAG, R. (2009) Investigation of factors influencing biogas production in a large-scale thermophilic municipal biogas plant. Applied Microbiology and Biotechnology, v. 84, n. 5, p. 987-1001.

ZAHEDI, S.; SALES, D.; ROMERO, L.I.; SOLERA, R. (2O13) Optimisation of single-phase dry-thermophilic anaerobic digestion under high organic loading rates of industrial municipal solid waste: Population dynamics. Bioresource Technology, v. 146, p. 109-117. 